\title{
Factors Involved in the In Vitro Fermentability of Short Carbohydrates in Static Faecal Batch Cultures
}

\author{
Eva Gietl,1, 2 Wim Mengerink, ${ }^{1}$ Jaap de Slegte, ${ }^{1}$ Glenn Gibson, ${ }^{2}$ \\ Robert Rastall, ${ }^{2}$ and Ellen van den Heuvel ${ }^{1}$ \\ ${ }^{1}$ FrieslandCampina Research, FrieslandCampina, 7400 AB Deventer, The Netherlands
${ }^{2}$ Department of Food and Nutritional Sciences, The University of Reading, Whiteknights, P.O. Box 226, Berkshire,
Reading RG6 6AP, UK
}

Correspondence should be addressed to Eva Gietl, eva.gietl@aevotis.com

Received 17 June 2012; Revised 13 November 2012; Accepted 13 November 2012

Academic Editor: R. J. Linhardt

Copyright ( $) 2012$ Eva Gietl et al. This is an open access article distributed under the Creative Commons Attribution License, which permits unrestricted use, distribution, and reproduction in any medium, provided the original work is properly cited.

\begin{abstract}
In recent years, research has focused on the positive effects of prebiotics on intestinal health and gut microbiota. The relationship between their chemical structure and their fermentation pattern by human intestinal microbiota is still not well understood. The aim of this study was to improve understanding of this relationship and identify factors that may be used to design galactooligosaccharides that reach more distal regions than commercial prebiotics which mainly target the proximal colon. The following factors were investigated: monomer type, linkage, substitution, and degree of polymerisation. Total organic acid production from sugars by faecal bacteria was fitted to a model which allowed an estimate of the time when half of the maximal organic acid concentration was reached $\left(T_{50}\right)$ in static faecal batch cultures. The different factors can be grouped by their effectiveness at prolonging fermentation time as follows: substitution is most effective, with methylgalactose, $\beta$-galactosepentaacetate, D-fucose, and galactitol fermented more slowly than D-galactose. Monomers and linkage also influence fermentation time, with L rhamnose, arabinose, melezitose, and xylose being fermented significantly slower than D-glucose $(P<0.05)$, maltose, isomaltose, cellobiose, and gentiobiose showing that Glc $\alpha 1-6 \mathrm{Glc}$ and Glc $\beta 1-4 \mathrm{Glc}$ were utilised slowest. Chain length had the smallest effect on fermentation time.
\end{abstract}

\section{Introduction}

Epidemiological data [1-4] indicate that a diet high in dietary fibres from vegetables and grains is correlated to a reduced risk of certain diseases in humans, among them colon cancer, ulcerative colitis, and cardiovascular disease. Experimental evidence suggests that the short-chain fatty acids (SCFA), butyric, acetic, and propionic acids [3-5], play a role in this risk reduction. They are produced by the intestinal microbiota as a result of dietary fibre fermentation.

Dietary fibres are plant materials, mostly storage carbohydrates or cell wall components, that cannot be digested in the human small intestine and reach the colon intact. They are available as substrates for the resident microbiota [6]. Some dietary fibres may also have prebiotic potential. Prebiotics are "non-digestible food ingredients that beneficially affect the host by selectively stimulating the growth and/or activity of one or a limited number of bacterial species already resident in the colon, and thus attempt to improve host health" [7]. Bacterial fermentation of carbohydrates in the colon results in the production of SCFA, mainly acetic, propionic, and butyric acid. Other organic acids also occur, such as lactic acid. The SCFA pattern, for example, the ratio of acetate, propionate, and butyrate to each other, is strongly determined by the fermented fiber/carbohydrate [8]. Each of them has positive effects on the health of the host. Butyrate has anticarcinogenic properties and contributes towards mucosal integrity by influencing the cell cycle progression of colonic epithelial cells [9-11]. Propionate may decrease cardiovascular disease risk by its influence on cholesterol synthesis [12], while acetate may improve cognitive function $[13,14]$. In vitro and in vivo data suggest that fermentable prebiotics, such as fructooligosaccharides (FOS) and galactooligosaccharides 
(GOS), are rapidly fermented in the proximal colon $[15,16]$. Therefore, their beneficial effects may be limited to the proximal part of the colon and of short duration.

Because the intestinal microflora uses mainly the available carbohydrates as energy source in the proximal region of the colon, carbohydrates become depleted in more distal areas and the microflora switches to proteolytic fermentation [17]. Protein breakdown and amino acid dissimilation generate harmful putrefactive substances such as ammonia, amines, phenols, and indoles [18]. Van Nuenen et al. [19] showed a higher in vitro production of ammonia when faecal samples from patients with inflammatory bowel disease (IBD: Crohn's disease as well as ulcerative colitis) were used as inocula. This may indicate that individuals with IBD host a more proteolytic microbiota and/or have a lower supply of carbohydrates to the colon.

By prolonging the availability of carbohydrates towards the distal part of the colon, increased saccharolytic fermentation might occur throughout the colon, and the production of harmful compounds of protein breakdown is reduced. This is underscored by data of McIntyre et al. [20], who demonstrated, in rats, that slowly fermented fibres resulted in increased concentrations of SCFA in the distal large bowel compared to more rapidly fermented carbohydrates.

There are many properties that influence the fermentation time of fibres. Olano-Martin et al. [21] showed that degree of polymerisation (DP) and methylation influenced fermentation time by comparing the metabolism of high and low methylated pectins and their oligosaccharides in vitro. Oligosaccharides with lower chain length were fermented preferentially which also has been demonstrated in vitro by other researchers [22, 23]. Van Laere et al. [24] showed that linear oligosaccharides were fermented quicker and by a wider variety of species than branched chain oligosaccharides in vitro. While it is also generally assumed that solubility predicts fermentability [6], other factors that could influence fermentation time have not been studied in this respect, such as monosaccharide composition, and the linkage between the monosaccharides.

In the present study we focus on factors that can be modified in the synthesis of GOS; GOS is enzymatically produced by $\beta$-galactosidase from lactose in a reversible reaction. The primary objective here was to investigate the relationship between carbohydrate structure and fermentability in order to identify factors that might prolong the fermentation time of GOS: (1) type of monomers (i.e., acceptor substrates different from lactose), (2) isomery of the monomers (e.g., L-sugars as acceptor substrates), (3) linkages between the monomers ( $\alpha 1-4, \alpha 1-6, \beta 1-4$, and $\beta 1-6)$, (4) the substitution of the side-groups/chains (reduction, acetylation, a methylation), and (5) variation in chain length (DP $<8)$. A further outcome was to determine if and how these factors would affect the SCFA pattern produced by human faecal microbiota which may provide benefits that exceed gut health.

\section{Materials and Methods}

If not otherwise specified, materials were obtained from Sigma.
2.1. Nonstirred, Non-pH-Controlled In Vitro Fermentations. Glass culture tubes containing $9 \mathrm{~mL}$ medium ( $\mathrm{pH} 7$ ) per litre: peptone $0.78 \mathrm{~g}$ (Oxoid), $\mathrm{NaCl} 0.49 \mathrm{~g}, \mathrm{Na}_{2} \mathrm{HPO}_{4} \cdot 12 \mathrm{H}_{2} \mathrm{O} 7.1 \mathrm{~g}$, $\mathrm{KH}_{2} \mathrm{PO}_{4} 1.6 \mathrm{~g}$, Bile salts no. 3 (Oxoid) $0.4 \mathrm{~g}$, cysteine $\cdot \mathrm{HCl}$ $0.5 \mathrm{~g}, \mathrm{~K}_{2} \mathrm{HPO}_{4} \cdot 3 \mathrm{H}_{2} \mathrm{O} 0.5 \mathrm{~g}, \mathrm{MgSO}_{4} 0.01 \mathrm{~g}, \mathrm{CaCl}_{2} \cdot 2 \mathrm{H}_{2} \mathrm{O}$ $0.007 \mathrm{~g}$, haemin-solution $(0.5 \mathrm{~g} / \mathrm{L}$; $) 10 \mathrm{~mL}$, Tween $802 \mathrm{~mL}$, vitamin $\mathrm{K} 110 \mu \mathrm{L}$, resazurin-solution $4 \mathrm{~mL}$. The medium was heat-sterilised and degassed by boiling, and the hot tubes were placed to cool in an anaerobic cabinet $\left(90 \% \mathrm{~N}_{2}, 5 \%\right.$ $\left.\mathrm{CO}_{2}, 5 \% \mathrm{H}_{2}\right)$ to maintain anaerobicity. To each tube, $0.5 \mathrm{~mL}$ faecal slurry and $0.5 \mathrm{~mL}$ carbohydrate-PBS solution $(10 \%$ $\mathrm{w} / \mathrm{v}$ ) were added. The fermentations were carried out in three parallel runs, one per faecal donor, for each carbohydrate. A glucose-PBS-solution was treated in the same way and used as a positive control. Incubation and sample collection were carried out in the anaerobic cabinet at $37^{\circ} \mathrm{C}$. The initial experiments were conducted over a period of $24 \mathrm{~h}$. Subsequent incubations were prolonged to first 48 , then $72 \mathrm{~h}$, as indicated below.

In vivo, acetate, propionate, and butyrate do not accumulate in the colon but are absorbed by the colonic mucosa $[25,26]$ while in static batch culture tests these short chain acids accumulate and could possibly inhibit microorganisms by the drop in $\mathrm{pH}$. To prevent the inactivation of microorganisms due to this accumulation the buffer concentration of the batch culture medium was increased such that the $\mathrm{pH}$ did not fall below pH 5 .

2.2. Faecal Slurry Preparation. Healthy adults who had not used antibiotics for at least three months donated stool samples (three males, one female; aged 27 to 60 years) prior to each experiment. None of the volunteers had any history of gastrointestinal disorder. All volunteers were eating a mixed Dutch diet. Within 30 min following defaecation, faecal slurries were prepared from 1 part freshly voided faecal sample and 9 parts prereduced phosphate-buffered saline (PBS) pH 7 (10\% w/v). For every experiment, three fresh faecal samples were obtained and immediately used.

2.3. Factors Studied. Table 1 states the manufacturers/suppliers of the test substrates.

2.4. Composition of Monomers, D-/L-Isomery, and Linkage. In separate experiments, substrates were tested at a starting concentration of $0.5 \%(\mathrm{w} / \mathrm{v})$ : monosaccharides, di- and trisaccharides, D- and L-isomers of arabinose and xylose, and the glucopyranosyl-D-glucoses D-maltose ( $\alpha 1-4)$, isomaltose $(\alpha 1-6)$, cellobiose $(\beta 1-4)$ and gentiobiose $(\beta 1-6)$ (Table 1$)$.

2.5. Substitution/Derivatisation. Methyl- $\beta$-galactopyranoside (methylgalactose; see Table 1 for manufacturers of the substrates used), $\beta$-galactose pentaacetate, $D$-fucose (deoxygalactose), and galactitol were studied at a final concentration of $1 \%(\mathrm{w} / \mathrm{v})$ to examine the influence of different substitutions on fermentation times. Instead of D-glucose, D-galactose was used as a positive control. In this experiment, the concentration of substrate was doubled, as compared to the other experiments, to make differences 
TABle 1: Substrates used in faecal batch culture experiments to determine influence of chain length, composition, and linkage on fermentation time.

\begin{tabular}{|c|c|c|c|c|c|}
\hline Sugar & DP & Monomer(s) & Linkage & Substitution/derivatisation & Manufacturer \\
\hline D-glucose & 1 & D-glucose & & & Sigma \\
\hline D-mannose & 1 & D-mannose & & & Sigma \\
\hline L-rhamnose & 1 & L-rhamnose & & 6-Deoxy-D-mannose & Sigma \\
\hline D-arabinose & 1 & D-arabinose & & & Sigma \\
\hline L-arabinose & 1 & L-arabinose & & & Merck \\
\hline D-xylose & 1 & D-xylose & & & Sigma \\
\hline L-xylose & 1 & L-xylose & & & Fluka \\
\hline D-fucose & 1 & D-galactose & & $\begin{array}{c}\text { Reduction } \\
\text { (6-Deoxy-D-galactose) }\end{array}$ & Fluka \\
\hline D-galactose & 1 & D-galactose & & & Merck \\
\hline Lactose & 2 & $\begin{array}{l}\text { D-glucose, } \\
\text { D-galactose }\end{array}$ & $\beta 1-4$ & & Sigma \\
\hline Lactulose & 2 & $\begin{array}{l}\text { D-galactose, } \\
\text { D-fructose }\end{array}$ & $\beta 1-4$ & & Sigma \\
\hline Sucrose & 2 & $\begin{array}{l}\text { D-glucose, } \\
\text { D-fructose }\end{array}$ & $\alpha 1-2$ & & Sigma \\
\hline D-maltose & 2 & D-glucose & $\alpha 1-4$ & & Sigma \\
\hline Isomaltose & 2 & D-glucose & $\alpha 1-6$ & & Sigma \\
\hline Cellobiose & 2 & D-glucose & $\beta 1-4$ & & Sigma \\
\hline Gentiobiose & 2 & D-glucose & $\beta 1-6$ & & Sigma \\
\hline Raffinose & 3 & $\begin{array}{l}\text { D-galactose, } \\
\text { D-glucose, } \\
\text { D-fructose }\end{array}$ & $\begin{array}{l}\alpha 1-6 \\
\alpha 2-1\end{array}$ & & Sigma \\
\hline Melezitose & 3 & $\begin{array}{l}\text { D-glucose, } \\
\text { D-fructose, } \\
\text { D-glucose }\end{array}$ & $\begin{array}{l}\alpha 1-3 \\
\beta 2-1\end{array}$ & & Sigma \\
\hline Vivinal-GOS & $1-8$ & $\begin{array}{c}\text { D-galactose, } \\
\text { D-glucose }\end{array}$ & $\beta 1-4, \beta 1-6$ & & $\begin{array}{l}\text { Royal Friesland } \\
\text { Foods }\end{array}$ \\
\hline Glucuronic acid & 1 & D-glucose & & $\begin{array}{c}\text { Uronic acid } \\
\text { (oxidation at C6) }\end{array}$ & Sigma \\
\hline Galacturonic acid & 1 & $\begin{array}{l}\text { D-galactose, } \\
\text { D-fructose }\end{array}$ & & $\begin{array}{c}\text { Uronic acid } \\
\text { (oxidation at C6) }\end{array}$ & Sigma \\
\hline Glucosamine & 1 & D-glucose & & amine & Sigma \\
\hline $\begin{array}{l}\mathrm{N} \text {-acetylated } \\
\text { glucosamine }\end{array}$ & 1 & D-glucose & & Acetylated amine & Sigma \\
\hline $\begin{array}{l}\text { Methyl- } \beta \text { - } \\
\text { Galactopyranoside }\end{array}$ & 1 & D-galactose & & Methylation & Fluka \\
\hline $\begin{array}{l}\beta \text {-galactose } \\
\text { pentaacetate }\end{array}$ & 1 & D-galactose & & Acetylation & Fluka \\
\hline Galactitol & 1 & D-galactose & & Reduction (reduction at C1) & Fluka \\
\hline
\end{tabular}

between the test substances more pronounced as $\beta$-galactose pentaacetate, and galactitol did not dissolve in the growth medium.

The sugar derivatives glucuronic acid, galacturonic acid, glucosamine, and $\mathrm{N}$-acetylated glucosamine (GlcNAc) were tested at a concentration of $0.5 \%(\mathrm{w} / \mathrm{v}$, Table 1$)$.

2.6. Chain Length. To determine the influence of chain length on fermentation time, different fractions of GOS
(Vivinal-GOS, FrieslandCampina Domo, Zwolle, The Netherlands) were tested with a starting concentration of $0.5 \%$ $(\mathrm{w} / \mathrm{v})$ total carbohydrates; Vivinal-GOS consisting mainly of mono-, di-, tetra-, and pentasaccharides, GOS ${ }^{0}$ (purified GOS) which was treated with lactase (Maxilact) and contained no monosaccharides (removed by ion-exchange chromatography) or lactose, and pools of purified GOS (Vivinal-GOS) which were fractionated on a Mitsubishi UBK-530 cation exchange column (Pharmacia XP 260, $1 \mathrm{~m}$ length) in aqueous liquid chromatography. The latter 
resulted in $\mathrm{GOS}^{1}$ (mostly tetra- and pentasaccharides), GOS ${ }^{2}$ (tri-, tetra-, and pentasaccharides), and $\mathrm{GOS}^{3}$ (disaccharides, not including lactose, tri-, and tetrasaccharides).

2.7. Sample Collection. The incubation time lasted $72 \mathrm{~h}$ in most experiments, except for tests on the substitution of oligosaccharides $(48 \mathrm{~h})$, the composition of monomers, the D-/L-isomery and chain length $(24 \mathrm{~h})$, as explained above. At incubation times of $0,2,4,6,8,24,48$, and $72 \mathrm{~h}$, samples of $1 \mathrm{~mL}$ were taken. Samples were centrifuged immediately (5 min, $16,110 \times \mathrm{g}$, room temperature) and the supernatants stored at $-20^{\circ} \mathrm{C}$.

2.8. SCFA Analysis. Supernatants were thawed at room temperature. Twenty $\mu \mathrm{L} \mathrm{K}_{4} \mathrm{Fe}(\mathrm{CN})_{6} \cdot 3 \mathrm{H}_{2} \mathrm{O}, 20 \mu \mathrm{L} \mathrm{ZnSO}_{4} \cdot 7 \mathrm{H}_{2} \mathrm{O}$ and $10 \mu \mathrm{L} 0.25 \mathrm{mM} \mathrm{NaOH}$ were added to $450 \mu \mathrm{L}$ supernatant. The samples were mixed after the addition of every reagent and centrifuged again $(5 \mathrm{~min}, 16110 \times \mathrm{g})$; supernatants were transferred into glass vials. A high performance liquid chromatography (HPLC) method, according to Guerrant [27], was used with an ion-exchange column (HPX-87H), $0.006 \mathrm{M} \mathrm{H}_{2} \mathrm{SO}_{4}$ as eluent, and UV-detection at $205 \mathrm{~nm}$. An organic acid mixture, containing lactate and the SCFA formate, acetate, propionate, butyrate, isobutyrate, valerate, and isovalerate, was employed in making a calibration curve.

2.9. Carbohydrate Recovery. Samples taken at $24 \mathrm{~h}$ were thawed and filter-sterilised. They were then diluted 500 times with $3 \%(\mathrm{w} / \mathrm{v})$ acetonitrile. Determinations of the test carbohydrates were then carried out on a DIONEX HPLC, with a PA1 (Ion exchange) column and pulsed amperometric detection (PAD). The eluents (12.5 mM NaOH, $125 \mathrm{mM}$ $\mathrm{NaOH}, 125 \mathrm{mM} \mathrm{NaOH}+500 \mathrm{mM} \mathrm{Na}$-acetate) formed a gradient from low-to-high molarity $\mathrm{NaOH}$.

This method allows the quantification of water-soluble sugars and their derivatives, but not of the oligosaccharide mixture of GOS, as this is a complex mixture of various sugars. Therefore, results for GOS were analysed semiquantitatively by calculating the percentage of the area under every peak compared to total area under the curve.

2.10. Data Analysis. Total SCFA and lactate production, that is, the sum of succinate, lactate, formate, acetate, propionate, butyrate, isobutyrate, valerate, and isovalerate, was fitted to a logistic growth model [28] using the advanced linear/nonlinear models-linear estimation of STATISTICA (StatSoft Benelux, Groningen).

The logistic model

$$
F=\frac{M P}{1+e^{-k\left(T-T_{50}\right)}},
$$

where $F$ is the amount of total organic acids at time $t, M P$ is the maximal production of total organic acids, $k$ is the fractional rate constant (which determines the speed of the organic acid production), $T$ is time of fermentation, and $T_{50}$ is time when total organic acid production reaches half of the maximum. $M P, k$, and $T_{50}$ were estimated for every sample. We chose the $T_{50}$ value for comparing sugars on time of fermentation because it is independent of the total organic acid production. Means were compared by $t$-test within an experiment. For interexperimental comparisons, values were corrected for D-glucose and then compared by $t$-test. The resulting $t$-values were corrected for false discovery rate to avoid false significances [29]. Differences were considered as significant if $P<0.05$.

The organic acid concentrations were treated as the $T_{50}$ values above.

\section{Results}

A correlation was found between total organic acid production and carbohydrate recovery, as measured during the first $24 \mathrm{~h}$ fermentation of $0.5 \%$ glucose and $1 \%(\mathrm{w} / \mathrm{v})$ galactose $\left(R^{2}=0.994\right.$ and 0.995 , resp., Figure 1). This indicates that the rate of production of organic acids is a good reflection of the rate of fermentation. Quantitative analysis of recovery was not possible for the different fractions of GOS using Dionex HPLC because it is a complex mixture of oligosaccharides. Therefore, organic acid production was used to compare the rate of fermentation of test substances differing in structural factors.

3.1. Composition of Monomers, D-/L-Isomery. Fermentation of the di- and trisaccharides resulted in a concentration of total organic acids of 29 to $41 \mathrm{mM}$ at $24 \mathrm{~h}$. In the other experiments regarding D-/L-isomery and monomers, total organic acid concentrations between 25 and $60 \mathrm{mM}$ were found (Table 2). Compared to D-glucose, fermentation of $\mathrm{D}$-arabinose, $\mathrm{L}$-xylose, and $\mathrm{D}$-mannose resulted in a significantly lower amount of lactate at $24 \mathrm{~h}(P=0.002$, $0.000,0.003$, resp., Table 2). Fermentation of D-glucose resulted in an acetate: propionate: butyrate $(\mathrm{A}: \mathrm{P}: \mathrm{B})$ ratio of $57: 20: 23$; lower acetate and higher butyrate proportions than in the other experiments. D-mannose and L-rhamnose fermentation resulted in an $\mathrm{A}: \mathrm{P}: \mathrm{B}$ ratio of $45: 29: 26$ and $46: 34: 20$, respectively, while the $\mathrm{D}$-glucose control in this experiment yielded mainly acetate $(82: 8: 10)$.

Fermentation of D-mannose, L-arabinose, L-rhamnose, melezitose, $\mathrm{D}$-xylose, $\mathrm{D}$-arabinose, and L-xylose resulted in significantly higher $T_{50}$ values than did the fermentation of D-glucose (Table 3). Based on HPLC analyses, only L-xylose was not completely utilised by $24 \mathrm{~h}$ of incubation (data not shown).

3.2. Linkage. Isomaltose yielded $32 \mathrm{mM}$ organic acids as maximal concentration, while the other substrates reached between 50 and $60 \mathrm{mM}$ at $24 \mathrm{~h}$. The fermentation products of isomaltose were mainly acetate and propionate $(\mathrm{A}: \mathrm{P}: \mathrm{B}$ ratio of $76: 14: 6$ ), whereas fermentation of cellobiose, maltose, and gentiobiose resulted mainly in lactate $(30,54$, and $44 \%$ of total organic acid production, resp.) and acetate ( $\mathrm{A}: \mathrm{P}: \mathrm{B}$ ratio of $54: 3: 1,48: 4: 1$, and $49: 2.5: 1$, resp.) production (Table 2).

D-maltose (Glc $\alpha 1-4 \mathrm{Glc})$, gentiobiose (Glc $\beta 1-6 \mathrm{Glc})$, cellobiose (Glc $\beta 1-4 \mathrm{Glc})$, and isomaltose (Glc $\alpha 1-6 \mathrm{Glc})$ had significantly higher $T_{50}$ values than D-glucose (Table 3 ). 


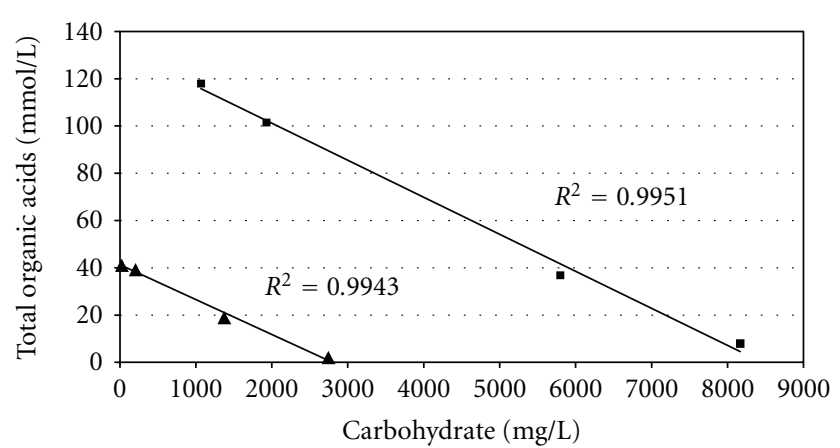

Figure 1: Correlation between total organic acid production, that is, the sum of acetate, propionate, isobutyrate, butyrate, isovalerate, and valerate, and carbohydrate consumption for $1 \%(\mathrm{w} / \mathrm{v})$ galactose (squares) and $0.5 \%(\mathrm{w} / \mathrm{v})$ glucose (triangles) in static faecal batch culture experiments $(n=3)$.

Nevertheless, less than $1 \%(\mathrm{w} / \mathrm{v})$ of the original substrate was recovered after $24 \mathrm{~h}$ fermentation (data not shown).

3.3. Substitution/Derivatisation. GlcNAc, glucosamine, galacturonate, and glucuronate fermentations resulted in significantly higher $T_{50}$ values than D-glucose fermentation (Table 3). Their total organic acid yields after $24 \mathrm{~h}$ were markedly lower, due to low lactate yields (Table 2). Concentrations of the branched-chain fatty acids, valerate and formate, were significantly lower in the glucuronic and galacturonic acid fermentations than in the positive control (data not shown). GlcNAc and glucosamine resulted in high concentrations of formate and lactate during the first $8 \mathrm{~h}$ of incubation (data not shown), which disappeared after $8 \mathrm{~h}$.

Galactitol and $\beta$-galactose pentaacetate did not dissolve in the growth medium, but remained as a precipitate. Fermentation of methylgalactose closely resembled the pattern of D-galactose fermentation while D-fucose, galactose pentaacetate, and galactitol yielded significantly lower lactate, and in the case of galactitol and D-fucose, acetate concentrations and reached significantly higher $T_{50}$ values (Tables 2 and 3).

3.4. Chain Length. Vivinal-GOS and D-glucose had almost identical organic acid production values. Vivinal-GOS (mainly DP 1 to 5 ) and GOS$^{0}$ (mainly DP 2 to 5 ) had the same estimated $T_{50}$ value as D-glucose. GOS ${ }^{1}$ (mainly DP 4 and 5), GOS 2 (DP 3 to 5), and $\mathrm{GOS}^{3}$ (DP 2 to 4) had longer fermentation times. $\mathrm{GOS}^{0}$ through $\mathrm{GOS}^{3}$ fermentation yielded significantly less lactate and $\mathrm{GOS}^{1}$ through $\mathrm{GOS}^{3}$ significantly more acetate than D-glucose and Vivinal-GOS fermentations.

GOS consist of galactose chains with a terminal glucose molecule. During fermentative hydrolysis, D-galactose and some D-glucose are released (Figure 2, 4 hours: D-galactose and D-glucose peaks appear) and subsequently consumed by the bacteria (Figure 2, 8 hours: D-galactose and D-glucose have disappeared again). As quantitative measurement of all peaks of GOS was not possible, the utilisation of substrate over time could only be shown semiquantitatively. Following
24 h incubation, only $6 \%$ of the initial Vivinal-GOS could be recovered and 8 to $12 \%$ of GOS $^{0}$ and the pools (data not shown). However, in all samples independent of substrate, peak 22 of the chromatogram was the most resistant to degradation (Figure 2).

\section{Discussion}

The present study was designed to investigate the different factors that affect the chemical structure of GOS and that can be changed in the synthesis of GOS. The approach was to use the isolated factors instead of synthesising new GOS and test these. The advantage of this approach was that more structure elements could be tested independent of each other. However, it has to be kept in mind that in vivo most of the mono- and disaccharides used would be digested and absorbed in the small intestine and not reach the colon.

This study has shown a structure-function relationship between factors, such as the substitution of side-chains, monomer composition and linkage, and fermentation time of carbohydrates in static faecal batch culture experiments. Furthermore, these factors not only affected the total amount of SCFA from which the $T_{50}$ was calculated, but also the SCFA ratios. Static batch culture experiments have widely been used to compare substrates in faecal fermentations, using either SCFA production or gas production [28, 30, 31] to characterise the rate of fermentation. In the present study, organic acid production was used for curve fitting and estimation of fermentation time because of a good correlation with carbohydrate recovery. Total organic acid production for $0.5 \%(\mathrm{w} / \mathrm{v})$ D-glucose varied between 40 and $70 \mathrm{mM}$ at $24 \mathrm{~h}$, which seems high but is comparable to literature data $[32,33]$. This variation may be due to a variation in the microbiota and subsequently its fermentative pathways [3436], leading to different ratios of SCFA to gas and ethanol production. The experiments were performed over several months, and the faecal samples were provided by the same four donors throughout the study. However, the microbial composition of the faecal samples was not analysed during the study so that changes in the faecal microbiota were not monitored. The monosaccharides D-arabinose, D-xylose, Dmannose, and L-rhamnose as well as glucosamine increased the concentration of propionate significantly compared to D-glucose $(P<0.05)$. This is comparable to Mortensen et al. [37] who also observed an increase in propionate for L-rhamnose, D-arabinose, and D-xylose. Hove et al. [38] report that SCFA pattern is influenced mostly by the substrate, and not by the bacterial composition of the faecal fermentation. Therefore, these sugars should be considered in the design of a potential new prebiotic oligosaccharide targeted at cardiovascular disease [12]. No differences were observed between D-glucose and D-galactose regarding total organic acid production over time. Table 2 shows that $0.5 \%$ D-glucose yielded from 40 to $70 \mathrm{mM}$ total organic acids in $24 \mathrm{~h}$, while $1 \% \mathrm{D}$-galactose yielded $101 \mathrm{mM}$ total organic acids in the same time. Therefore, D-galactose was chosen as a positive control in the substitution experiment. By using a positive control within each experiment, fermentation times 
TABLE 2: Concentration of lactate and SCFA after $24 \mathrm{~h}$ of fermentation. Substrates $(0.5 \%(\mathrm{w} / \mathrm{v})$ except substitution group: $1 \%(\mathrm{w} / \mathrm{v}))$ were fermented anaerobically in static faecal batch culture incubations $(n=3)$.

\begin{tabular}{|c|c|c|c|c|c|c|c|c|c|c|c|}
\hline & & Lactate & \pm Stdev & Acetate & $\begin{array}{l} \pm \text { Stdev } \\
\mathrm{l} / \mathrm{L}\end{array}$ & Propionate & \pm Stdev & Butyrate & \pm Stdev & $\begin{array}{c}\text { Total } \\
\text { organic } \\
\text { acids }\end{array}$ & \pm Stdev \\
\hline \multirow{14}{*}{$\begin{array}{l}\text { Monomer } \\
\text { composition }\end{array}$} & Glucose & $16.09^{\mathrm{a}}$ & 1.14 & 20.08 & 1.36 & $3.61^{\mathrm{a}}$ & 1.66 & 0.00 & 0.00 & $41.83^{\mathrm{ab}}$ & 3.64 \\
\hline & L-arabinose & $18.65^{\mathrm{abc}}$ & 5.00 & 24.25 & 1.76 & $6.19^{\mathrm{ab}}$ & 2.61 & 0.00 & 0.00 & $51.46^{\mathrm{b}}$ & 3.63 \\
\hline & D-arabinose & $0.23^{\mathrm{b}}$ & 0.40 & 19.78 & 4.89 & $16.91^{\mathrm{cd}}$ & 1.79 & 0.00 & 0.00 & $38.18^{\mathrm{a}}$ & 5.12 \\
\hline & L-xylose & $0.53^{\mathrm{b}}$ & 0.56 & 19.20 & 11.34 & $2.87^{\mathrm{a}}$ & 0.23 & 0.95 & 0.82 & $24.90^{\mathrm{ab}}$ & 13.00 \\
\hline & D-xylose & $4.79^{\mathrm{abc}}$ & 4.19 & 19.92 & 2.48 & $13.89^{c e}$ & 1.52 & 0.00 & 0.00 & $40.03^{\mathrm{a}}$ & 5.65 \\
\hline & Glucose & $0.00^{\mathrm{a}}$ & 0.00 & 16.95 & 0.60 & $6.07^{\mathrm{a}}$ & 1.57 & 6.92 & 0.37 & $32.16^{\mathrm{ab}}$ & 4.77 \\
\hline & Lactose & $6.99^{\mathrm{abc}}$ & 12.11 & 19.72 & 2.06 & $3.98^{\mathrm{a}}$ & 0.02 & 8.76 & 3.92 & $41.06^{\mathrm{ab}}$ & 9.11 \\
\hline & Lactulose & $3.49^{\mathrm{ac}}$ & 6.05 & 23.75 & 3.20 & $3.39^{\mathrm{a}}$ & 0.29 & 4.06 & 2.86 & $37.39^{\mathrm{a}}$ & 4.13 \\
\hline & Melezitose & $1.73^{\mathrm{a}}$ & 3.00 & 20.50 & 1.51 & $5.55^{\mathrm{a}}$ & 1.43 & 5.02 & 1.34 & $36.47^{\mathrm{ab}}$ & 3.60 \\
\hline & Raffinose & $1.76^{\mathrm{a}}$ & 3.04 & 19.10 & 2.22 & $4.55^{\mathrm{a}}$ & 0.90 & 6.60 & 3.41 & $33.53^{\mathrm{ab}}$ & 0.70 \\
\hline & Sucrose & $0.00^{\mathrm{a}}$ & 0.00 & 0.95 & 0.92 & $14.22^{\text {aef }}$ & 4.10 & 1.93 & 1.90 & $29.93^{\mathrm{b}}$ & 4.69 \\
\hline & Glucose & $29.62^{\mathrm{a}}$ & 7.18 & 27.73 & 5.17 & $3.21^{\mathrm{a}}$ & 1.80 & 2.82 & 1.66 & 67.69 & 4.73 \\
\hline & D-mannose & $16.84^{\mathrm{cb}}$ & 6.88 & 15.78 & 2.02 & $10.18^{\mathrm{bdf}}$ & 1.35 & 9.33 & 1.22 & 52.20 & 11.96 \\
\hline & L-rhamnose & $0.10^{a b c}$ & 0.17 & 25.61 & 5.13 & $19.09^{c}$ & 1.26 & 10.99 & 4.34 & 60.74 & 1.98 \\
\hline \multirow{5}{*}{ Linkage } & Glucose & $25.51^{\mathrm{a}}$ & 1.11 & $23.26^{\mathrm{abc}}$ & 6.20 & $1.30^{\mathrm{a}}$ & 0.69 & 0.32 & 0.14 & $52.99^{\mathrm{ac}}$ & 4.13 \\
\hline & Maltose & $15.60^{\mathrm{b}}$ & 2.24 & $28.53^{b}$ & 2.64 & $1.79^{\mathrm{b}}$ & 0.70 & 0.75 & 0.64 & $52.35^{\mathrm{a}}$ & 1.38 \\
\hline & Isomaltose & $0.00^{c}$ & 0.00 & $24.78^{c}$ & 2.28 & $4.67^{\mathrm{ab}}$ & 3.04 & 1.34 & 1.30 & $32.05^{\mathrm{b}}$ & 2.68 \\
\hline & Cellobiose & $26.92^{\mathrm{a}}$ & 2.56 & $14.10^{\mathrm{a}}$ & 1.69 & $1.93^{\mathrm{ab}}$ & 0.69 & 0.59 & 0.55 & $49.95^{\mathrm{ac}}$ & 4.75 \\
\hline & Gentiobiose & $26.66^{\mathrm{a}}$ & 0.44 & $29.76^{\mathrm{b}}$ & 2.25 & $1.48^{\mathrm{ab}}$ & 0.39 & 0.56 & 0.14 & $60.12^{c}$ & 1.25 \\
\hline \multirow{5}{*}{ Substitution } & Galactose & $38.11^{\mathrm{a}}$ & 2.73 & $56.75^{\mathrm{a}}$ & 2.37 & $4.39^{\mathrm{ab}}$ & 1.44 & 0.45 & 0.15 & $101.44^{a}$ & 6.01 \\
\hline & Methylgalactose & $34.76^{\mathrm{a}}$ & 3.09 & $50.89^{\mathrm{b}}$ & 0.36 & $3.51^{\mathrm{a}}$ & 0.95 & 0.51 & 0.53 & $91.03^{\mathrm{a}}$ & 4.74 \\
\hline & $\begin{array}{c}\text { Galactose } \\
\text { pentaacetate }\end{array}$ & $0.10^{\mathrm{b}}$ & 0.17 & $40.66^{\mathrm{abc}}$ & 7.82 & $4.28^{\mathrm{ab}}$ & 1.23 & 0.58 & 1.01 & $47.88^{b}$ & 9.53 \\
\hline & Galactitol & $2.21^{\mathrm{b}}$ & 2.48 & $15.28^{\mathrm{cd}}$ & 13.23 & $4.41^{\mathrm{ab}}$ & 1.24 & 0.63 & 1.09 & $24.52^{b c}$ & 12.78 \\
\hline & Fucose & $0.00^{\mathrm{b}}$ & 0.00 & $25.61^{\mathrm{d}}$ & 4.85 & $11.75^{\mathrm{b}}$ & 4.04 & 1.56 & 1.45 & $40.45^{c}$ & 9.6 \\
\hline \multirow{5}{*}{ Derivatisation } & Glucose & $27.48^{\mathrm{a}}$ & 4.04 & $27.80^{\mathrm{ac}}$ & 0.25 & $1.89^{a}$ & 0.19 & 0.51 & 0.45 & $62.24^{\mathrm{a}}$ & 4.17 \\
\hline & Glucuronic acid & $3.41^{\mathrm{b}}$ & 2.81 & $23.71^{\mathrm{abc}}$ & 6.40 & $3.13^{\mathrm{ab}}$ & 0.93 & 5.51 & & $33.74^{\mathrm{b}}$ & 6.00 \\
\hline & Galacturonic acid & $0.67^{\mathrm{ab} \dagger}$ & 0.19 & $20.31^{\mathrm{b}}$ & 0.74 & $4.11^{\mathrm{ab}}$ & 1.54 & 0.00 & 0.00 & $32.86^{\mathrm{b}}$ & 8.48 \\
\hline & Glucosamine & $0.33^{\mathrm{b}}$ & 0.47 & $15.68^{\mathrm{ab}}$ & 6.14 & $4.99^{\mathrm{b}}$ & 0.45 & 3.11 & 0.82 & $27.08^{b}$ & 10.54 \\
\hline & GlcNAc & $0.73^{\mathrm{b}}$ & 0.64 & $32.43^{c}$ & 3.97 & $4.89^{\mathrm{ab}}$ & 1.93 & $5.08^{\dagger}$ & 4.77 & $45.90^{\mathrm{b}}$ & 3.03 \\
\hline \multirow{6}{*}{ Chain length } & Glucose & $18.68^{\mathrm{ab}}$ & 3.06 & $20.74^{\mathrm{a}}$ & 2.17 & 1.57 & 0.25 & 0.27 & 0.26 & 41.56 & 4.00 \\
\hline & Vivinal-GOS & $18.14^{\mathrm{a}}$ & 2.25 & $21.67^{\mathrm{a}}$ & 0.97 & 1.41 & 0.28 & 0.22 & 0.22 & 41.87 & 1.73 \\
\hline & $\mathrm{GOS}^{0}$ & $13.49^{\mathrm{bc}}$ & 1.25 & $22.81^{\mathrm{ab}}$ & 1.10 & 1.30 & 0.25 & 0.36 & 0.51 & 38.28 & 1.05 \\
\hline & $\mathrm{GOS}^{1}$ & $10.91^{\mathrm{c}}$ & 0.64 & $25.13^{b}$ & 2.28 & 1.42 & 0.30 & 0.40 & 0.56 & 37.91 & 2.12 \\
\hline & $\mathrm{GOS}^{2}$ & $14.94^{\mathrm{c}}$ & 2.34 & $25.64^{\mathrm{b}}$ & 1.96 & 1.61 & 0.21 & 0.31 & 0.35 & 42.61 & 3.37 \\
\hline & $\mathrm{GOS}^{3}$ & $13.51^{\mathrm{ac}}$ & 0.83 & $24.28^{b}$ & 1.33 & 1.31 & 0.11 & 0.25 & 0.26 & 39.48 & 1.02 \\
\hline
\end{tabular}

GOS: galactooligosaccharide.

Different superscript letters indicate significant differences within each group $(P<0.05)$.

${ }^{\dagger} n=2$.

of substrates can be compared within each data set, and, with adjustment to the control, across data sets.

Fermentation time of different substrates varied considerably. Sugars such as melezitose, L-rhamnose, Larabinose, D-arabinose, L-xylose, D-xylose, galacturonate, and glucuronate were fermented significantly more slowly than the digestible sugars D-glucose and sucrose and, as expected, more slowly than the indigestible (by human small intestinal enzymes) sugars raffinose and lactulose. A prolonged fermentation of L-rhamnose as compared 
TABle 3: Halftime of fermentation, expressed as $T_{50}$ values (hours), of substrates $(0.5 \%(\mathrm{w} / \mathrm{v})$ except substitution group: $1 \%$ (w/v)) in static faecal batch culture incubations $(n=3)$. Production of total organic acids over 24,48 and $72 \mathrm{~h}$ was used to calculate $T_{50}$ values.

\begin{tabular}{|c|c|c|c|}
\hline & & $T_{50}[$ hours $]$ & SE \\
\hline \multirow{14}{*}{ Monomer composition } & Glucose & $3.46^{\mathrm{a}}$ & \pm 0.46 \\
\hline & Raffinose & $3.53^{\mathrm{ab}}$ & \pm 0.28 \\
\hline & Sucrose & $3.94^{\mathrm{ab}}$ & \pm 0.28 \\
\hline & Lactulose & $4.08^{\mathrm{ab}}$ & \pm 0.36 \\
\hline & Lactose & $4.18^{\mathrm{ab}}$ & \pm 0.08 \\
\hline & Melezitose $^{\dagger}$ & $8.65^{\mathrm{d}}$ & \pm 0.90 \\
\hline & Glucose & $4.42^{\mathrm{a}}$ & \pm 0.66 \\
\hline & D-mannose & $5.51^{\mathrm{b}}$ & \pm 0.33 \\
\hline & L-rhamnose & $8.25^{\mathrm{d}}$ & \pm 0.91 \\
\hline & Glucose & $5.51^{\mathrm{a}}$ & \pm 0.44 \\
\hline & L-arabinose & $7.83^{c}$ & \pm 0.31 \\
\hline & D-xylose & $10.27^{\mathrm{d}}$ & \pm 0.51 \\
\hline & D-arabinose & $11.31^{\mathrm{d}}$ & \pm 0.45 \\
\hline & L-xylose & $11.72^{\mathrm{d}}$ & \pm 0.54 \\
\hline \multirow{5}{*}{ Linkage } & Glucose & $5.21^{\mathrm{a}}$ & \pm 0.26 \\
\hline & Maltose & $5.93^{\mathrm{b}}$ & \pm 0.45 \\
\hline & Gentiobiose & $6.23^{c}$ & \pm 0.17 \\
\hline & Cellobiose & $7.33^{\mathrm{c}}$ & \pm 0.29 \\
\hline & Isomaltose & $7.45^{\mathrm{d}}$ & \pm 0.88 \\
\hline \multirow{5}{*}{ Substitution } & Galactose & $11.09^{\mathrm{ac}}$ & \pm 1.46 \\
\hline & Methylgalactose & $15.93^{\mathrm{ab}}$ & \pm 0.24 \\
\hline & Galactose penta-acetate & $20.65^{\mathrm{d}}$ & \pm 0.62 \\
\hline & Galactitol & $24.35^{\mathrm{bd}}$ & \pm 1.61 \\
\hline & D-Fucose & $19.49^{c}$ & \pm 1.14 \\
\hline \multirow{5}{*}{ Derivatisation } & Glucose & $3.90^{\mathrm{a}}$ & \pm 0.22 \\
\hline & GlcNAc & $4.87^{\mathrm{b}}$ & \pm 0.14 \\
\hline & Glucosamine & $5.77^{\mathrm{b}}$ & \pm 0.98 \\
\hline & Galacturonic acid & $10.85^{c}$ & \pm 1.26 \\
\hline & Glucuronic acid $^{\dagger}$ & $11.63^{c}$ & \pm 0.75 \\
\hline \multirow{6}{*}{ Chain length } & Glucose & $4.19^{\mathrm{a}}$ & \pm 0.12 \\
\hline & Vivinal-GOS & $4.17^{\mathrm{a}}$ & \pm 0.16 \\
\hline & $\mathrm{GOS}^{0}$ & $4.37^{\mathrm{ac}}$ & \pm 0.18 \\
\hline & $\mathrm{GOS}^{1}$ & $4.92^{\mathrm{b}}$ & \pm 0.14 \\
\hline & $\mathrm{GOS}^{2}$ & $5.02^{\mathrm{b}}$ & \pm 0.12 \\
\hline & $\mathrm{GOS}^{3}$ & $4.82^{\mathrm{bc}}$ & \pm 0.16 \\
\hline
\end{tabular}

GOS: galactooligosaccharide.

Different superscript letters indicate significant differences within each group $(P<0.05)$.

${ }^{\dagger} n=2$.

to L-mannose had been reported previously [37], which confirms the results of the present study.

Not in all instances di- or trisaccharides were more slowly fermented than monosaccharides. This was the case for lactose, lactulose, raffinose, and sucrose. Mortensen et al. [37] did not show a further increase in total SCFA after $6 \mathrm{~h}$ fermentation of D-glucose, D-galactose, lactose (Gal $\beta 1-4 \mathrm{Glc})$, and lactulose (Gal $\beta 1-4 \mathrm{Fru})$, either, confirming our results that disaccharides are not per se fermented more slowly than monosaccharides. In the present study, melezitose (Glc $\beta 1$-3Fru $\alpha 2$-1Glc) was the only trisaccharide that was metabolised significantly slower than lactulose. This 

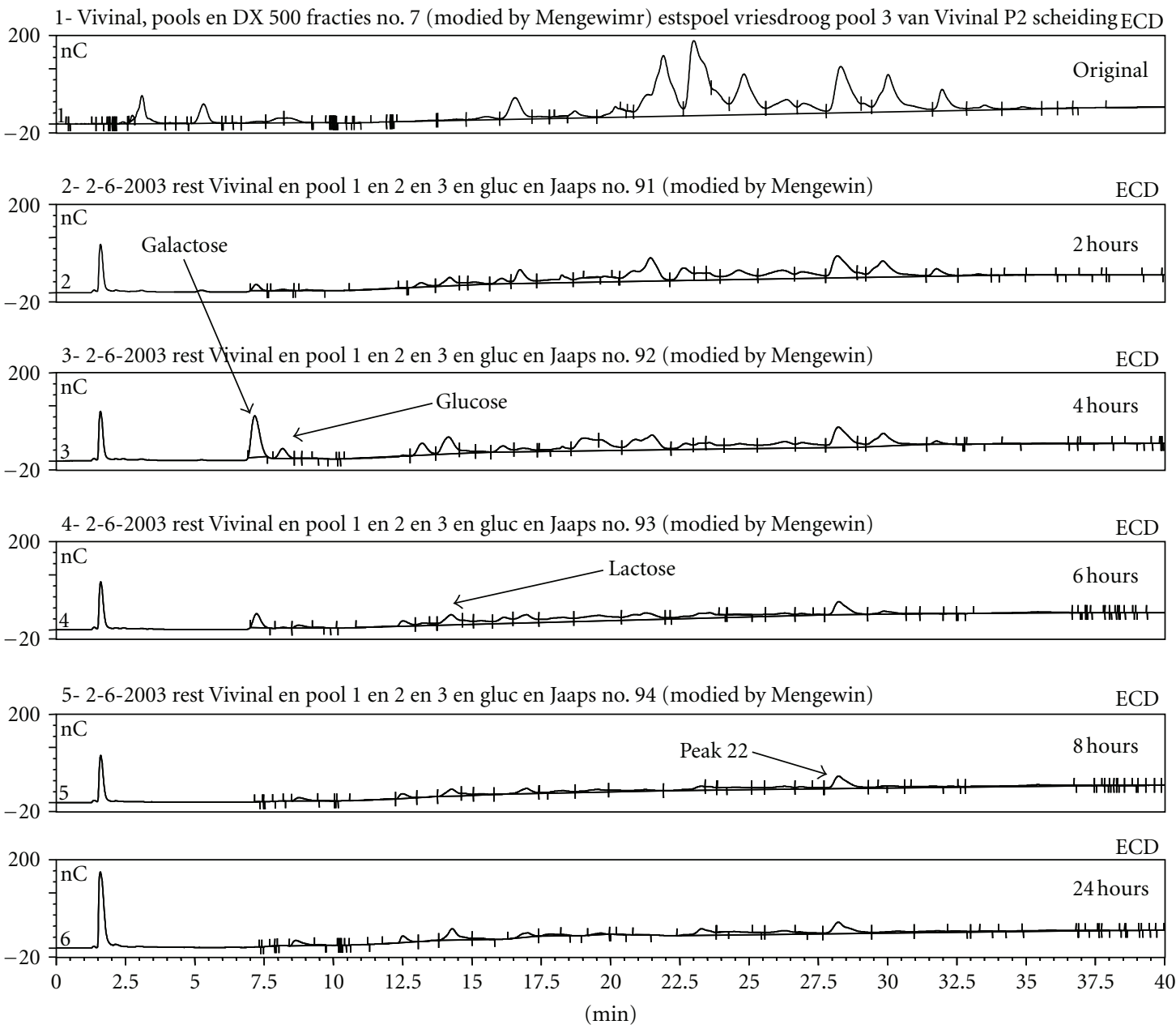

FIgure 2: Dionex-HPLC chromatogram of the galactooligosaccharide mixture GOS $^{3}$ breakdown over $24 \mathrm{~h}$ measured in cell-free fermentation supernatants. Static faecal batch culture fermentations were carried out in an anaerobic cabinet with a starting concentration of $\mathrm{GOS}^{3}$ of $0.5 \%(\mathrm{w} / \mathrm{v})$. Samples were taken after 2, 4, 6, 8, and $24 \mathrm{~h}$ of incubation. The oligosaccharide which is represented by peak 22 seemed to be resistant to fermentation.

may be due to the Glc $\beta 1-3$ Fru- linkage, as 1-3 bonds occur less often naturally than 1-4 and 1-6 bonds [39].

$\mathrm{D}$-xylose and L- and D-arabinose can all be found in natural polysaccharides, whereas L-xylose is less common. The deduction that L-xylose might therefore be more slowly fermented than D-xylose seemed to be confirmed by the presence of L-xylose after $24 \mathrm{~h}$ of fermentation. However, this was not confirmed by the half-time of SCFA production for L-xylose. All isomers were fermented significantly more slowly than $\mathrm{D}$-glucose. It might be possible to design a more distally fermented prebiotic, by synthesising GOS with arabinose or xylose as acceptor substrates, especially because xylan and arabinogalactan degrading enzymes are found in bifidobacteria [36] which are common target organisms of prebiotics because of their beneficial effects on gut health $[40,41]$. This is underscored by the results of Van Craeyveld et al. showing that short arabinoxylooligosaccharides (DP 3) increased caecal bifidobacteria numbers, while long arabinoxylooligosaccharides suppressed protein fermentation [42]. The latter indicates distal fermentation.
Another design for distally fermented galacto-oligosaccharides would be to include the linkages Glc $\alpha 1-6 \mathrm{Glc}$ (i.e., isomaltose) and Glc $\beta 1-4 \mathrm{Glc}$ (i.e., cellobiose) which were more slowly fermented. Sanz et al. [43] showed that isomaltose and cellobiose also favoured the growth of desirable bacteria (e.g., bifidobacteria) in relation to the growth of undesirable bacteria compared to FOS.

In addition to different acceptor substrates for the design of a distally fermented GOS, derivatisation, and substitution of GOS seems promising. The slower fermentation of $\beta$ galactose pentaacetate was not surprising because, in general, solubility and fermentability are correlated, at least when polysaccharides are tested [44]. Fucose and galactitol were both fermented more slowly. Since D-fucose and galactitol are each reduced forms of D-galactose, it might be interesting to reduce GOS to make it less fermentable. While glucosamine was fermented as quickly as D-glucose, GlcNAc, galacturonate, and glucuronate were utilized more slowly. This is in agreement with results from Mortensen et al. [37], who still showed an increase in SCFA concentrations 
between 6 and $24 \mathrm{~h}$ of fermentation for glucuronate and galacturonate.

The comparison between different fractions of GOS did not confirm the hypothesis that a GOS mixture with a higher DP would be fermented more slowly than one with a lower DP. However, it must be kept in mind that the DP of the GOS mixture was less than eight; higher DP oligosaccharides may still display increased fermentation time. Interestingly, there was a difference in the lactate and acetate production from different GOS fractions. GOS consist of galactose chains with a terminal glucose molecule. Different metabolic endproducts due to different chain lengths suggest that shortchain oligosaccharides of different DPs modulate the activity of the microbiota via a change in the bacterial composition. In batch culture experiments investigating the effect of DP of short-chain oligosaccharides on the faecal microflora, Sanz et al. observed that lower DP oligosaccharides (DP 23) generally score higher on the prebiotic index, indicating a beneficial modulation of the bacterial community, than higher DP oligosaccharides (DP 6-10) $[45,46]$.

From a multiple comparison (corrected for D-glucose when possible), the different factors can be grouped by their effectiveness at prolonging fermentation as follows: substitution is most effective, followed by the composition of monomers and linkage type. The chain length (within a DP $\leq 8$ ) is the least effective in prolonging fermentation time. It must be remembered, however, that these studies were performed using static batch cultures, which still need to be confirmed in vivo.

These factors could be used in the design of novel GOS to create a more distally fermentable prebiotic. The effectiveness of these new carbohydrates needs to be tested in vitro and in vivo.

\section{Acknowledgments}

This work was supported by the European Commission under the Marie Curie Intra-European Fellowship Program (Project QLK1-GH-01-60056-03) and by Friesland Coberco Dairy Foods (now FrieslandCampina). There were no conflicts of interest. Further, we want to thank Kieran Tuohy, Cordula Lindner, Veronika Nieder for their suggestions and sound advice; Alfred Bonte for his great help with the HPLC; Roy Beernink for his help with the fermentations; Rudy de Wit for his help with the curve-fitting. E. Gietl, E. van den Heuvel, J. de Slegte, G. Gibson, and R. Rastall designed research; E. Gietl and W. Mengerink conducted research; E. Gietl analyzed the data; E. Gietl, E. van den Heuvel, R. Rastall, and G. Gibson wrote the paper; E. Gietl had primary responsibility for final content. All authors read and approved the final document.

\section{References}

[1] D. P. Burkitt, "Related disease-related cause?" The Lancet, vol. 2, no. 7632, pp. 1229-1231, 1969.

[2] F. Levi, C. Pasche, C. La Vecchia, F. Lucchini, and S. Franceschi, "Food groups and colorectal cancer risk," British Journal of Cancer, vol. 79, no. 7-8, pp. 1283-1287, 1999.
[3] W. Scheppach, H. Sommer, T. Kirchner et al., "Effect of butyrate enemas on the colonic mucosa in distal ulcerative colitis," Gastroenterology, vol. 103, no. 1, pp. 51-56, 1992.

[4] B. F. Hinnebusch, S. Meng, J. T. Wu, S. Y. Archer, and R. A. Hodin, "The effects of short-chain fatty acids on human colon cancer cell phenotype are associated with histone hyperacetylation," Journal of Nutrition, vol. 132, no. 5, pp. 1012-1017, 2002.

[5] S. Tedelind, F. Westberg, M. Kjerrulf, and A. Vidal, "Antiinflammatory properties of the short-chain fatty acids acetate and propionate: a study with relevance to inflammatory bowel disease," World Journal of Gastroenterology, vol. 13, no. 20, pp. 2826-2832, 2007.

[6] A. D. Blackwood, J. Salter, P. W. Dettmar, and M. F. Chaplin, "Dietary fibre, physicochemical properties and their relationship to health," Journal of The Royal Society for the Promotion of Health, vol. 120, no. 4, pp. 242-247, 2000.

[7] G. R. Gibson and M. B. Roberfroid, "Dietary modulation of the human colonic microbiota: introducing the concept of prebiotics," Journal of Nutrition, vol. 125, no. 6, pp. 1401-1412, 1995.

[8] I. R. Rowland, C. J. Rumney, J. T. Coutts, and L. C. Lievense, "Effect of Bifidobacterium longum and inulin on gut bacterial metabolism and carcinogen-induced aberrant crypt foci in rats," Carcinogenesis, vol. 19, no. 2, pp. 281-285, 1998.

[9] B. L. Pool-Zobel, S. L. Abrahamse, and G. Rechkemmer, "Protective effects of short-chain fatty acids on early events of carcinogenesis: antigenotoxic effects of butyrate in rat and human colon cells," in Proceedings of COST Action 92th Workshop on Dietary Fibre and Fermentation in the Colon, pp. 350-357, Espoo, Finland, 1996.

[10] H. K. Biesalski, P. Fürst, H. Kasper et al., Ernährungsmedizin. 2. Überarbeitete Auflage, Georg Thieme, Stuttgart, Germany, 1999.

[11] T. R. Licht, M. Hansen, M. Poulsen, and L. O. Dragsted, "Dietary carbohydrate source influences molecular fingerprints of the rat faecal microbiota," BMC Microbiology, vol. 6, article 98, 2006.

[12] J. M. W. Wong, R. De Souza, C. W. C. Kendall, A. Emam, and D. J. A. Jenkins, "Colonic health: fermentation and short chain fatty acids," Journal of Clinical Gastroenterology, vol. 40, no. 3, pp. 235-243, 2006.

[13] G. A. Dienel and N. F. Cruz, "Astrocyte activation in working brain: energy supplied by minor substrates," Neurochemistry International, vol. 48, no. 6-7, pp. 586-595, 2006.

[14] M. T. Wyss, B. Weber, V. Treyer et al., "Stimulation-induced increases of astrocytic oxidative metabolism in rats and humans investigated with 1-11C-acetate," Journal of Cerebral Blood Flow and Metabolism, vol. 29, no. 1, pp. 44-56, 2009.

[15] A. J. McBain and G. T. Macfarlane, "Modulation of genotoxic enzyme activities by non-digestible oligosaccharide metabolism in in-vitro human gut bacterial ecosystems," Journal of Medical Microbiology, vol. 50, no. 9, pp. 833-842, 2001.

[16] G. Tzortzis, A. K. Goulas, J. M. Gee, and G. R. Gibson, "A novel galactooligosaccharide mixture increases the bifidobacterial population numbers in a continuous in vitro fermentation system and in the proximal colonic contents of pigs in vivo," Journal of Nutrition, vol. 135, no. 7, pp. 1726-1731, 2005.

[17] G. T. Macfarlane, G. R. Gibson, and J. H. Cummings, "Comparison of fermentation reactions in different regions of the human colon," Journal of Applied Bacteriology, vol. 72, no. 1, pp. 57-64, 1992.

[18] G. T. Macfarlane and A. J. McBain, "The human colonic microbiota," in Colonic Microbiota, Nutrition and Health, G. 
R. Gibson MB Roberfroid, Ed., pp. 1-25, Kluwer Academic Publishers, Dordrecht, The Netherlands, 1999.

[19] M. H. M. C. Van Nuenen, K. Venema, J. C. J. Van Der Woude, and E. J. Kuipers, "The metabolic activity of fecal microbiota from healthy individuals and patients with inflammatory bowel disease," Digestive Diseases and Sciences, vol. 49, no. 3, pp. 485-491, 2004.

[20] A. McIntyre, G. P. Young, T. Taranto, P. R. Gibson, and P. B. Ward, "Different fibers have different regional effects on luminal contents of rat colon," Gastroenterology, vol. 101, no. 5, pp. 1274-1281, 1991.

[21] E. Olano-Martin, K. C. Mountzouris, G. R. Gibson, and R. A. Rastall, "In vitro fermentability of dextran, oligodextran and maltodextrin by human gut bacteria," British Journal of Nutrition, vol. 83, no. 3, pp. 247-255, 2000.

[22] E. Olano-Martin, G. R. Gibson, and R. A. Rastall, "Comparison of the in vitro bifidogenic properties of pectins and pecticoligosaccharides," Journal of Applied Microbiology, vol. 93, no. 3, pp. 505-511, 2002.

[23] S. Perrin, C. Fougnies, J. P. Grill, H. Jacobs, and F. Schneider, "Fermentation of chicory fructo-oligosaccharides in mixtures of different degrees of polymerization by three strains of bifidobacteria," Canadian Journal of Microbiology, vol. 48, no. 8, pp. 759-763, 2002.

[24] K. M. J. Van Laere, M. Bosveld, H. A. Schols et al., "Fermentative degradation of plant cell wall derived oligosaccharides by intestinal bacteria," in Proceedings of the International Symposium on "Non-Digestible Oligosaccharides: Healthy Food for the Colon", R. Hartemink, Ed., pp. 37-46, Wageningen Graduate School VLAG, 1997.

[25] H. Ruppin, S. Bar-Meir, and K. H. Soergel, "Absorption of short-chain fatty acids by the colon," Gastroenterology, vol. 78, no. 6, pp. 1500-1507, 1980.

[26] J. A. Vogt and T. M. S. Wolever, "Fecal acetate is inversely related to acetate absorption from the human rectum and distal colon," Journal of Nutrition, vol. 133, no. 10, pp. 31453148, 2003.

[27] G. O. Guerrant, M. A. Lambert, and C. W. Moss, "Analysis of short-chain acids from anaerobic bacteria by highperformance liquid chromatography," Journal of Clinical Microbiology, vol. 16, no. 2, pp. 355-360, 1982.

[28] J. L. Campbell, C. V. Williams, and J. H. Eisemann, "Fecal inoculum can be used to determine the rate and extent of in vitro fermentation of dietary fiber sources across three lemur species that differ in dietary profile: varecia variegata, Eulemur fulvus and Hapalemur griseus," Journal of Nutrition, vol. 132, no. 10, pp. 3073-3080, 2002.

[29] Y. Benjamini and Y. Hochberg, "Controlling the false discovery rate: a practical and powerful approach to multiple testing," Journal of the Royal Statistical Society B, vol. 57, pp. 289-300, 1995.

[30] E. Bauer, B. A. Williams, C. Voigt, R. Mosenthin, and M. W. A. Verstegen, "Microbial activities of faeces from unweaned and adult pigs, in relation to selected fermentable carbohydrates," Animal Science, vol. 73, no. 2, pp. 313-322, 2001.

[31] M. R. Smiricky-Tjardes, E. A. Flickinger, C. M. Grieshop, L. L. Bauer, M. R. Murphy, and G. C. Fahey, "In vitro fermentation characteristics of selected oligosaccharides by swine fecal microflora," Journal of Animal Science, vol. 81, no. 10, pp. 2505-2514, 2003.

[32] A. J. Vince, N. I. McNeil, J. D. Wager, and O. M. Wrong, "The effect of lactulose, pectin, arabinogalactan and cellulose on the production of organic acids and metabolism of ammonia by intestinal bacteria in a faecal incubation system," British Journal of Nutrition, vol. 63, no. 1, pp. 17-26, 1990.

[33] P. J. Wood, E. Arrigoni, S. Shea Miller, and R. Amadò, "Fermentability of oat and wheat fractions enriched in $\beta$ glucan using human fecal inoculation," Cereal Chemistry, vol. 79, no. 3, pp. 445-454, 2002.

[34] N. Peekhaus and T. Conway, "What's for dinner?: entnerDoudoroff metabolism in Escherichia coli," Journal of Bacteriology, vol. 180, no. 14, pp. 3495-3502, 1998.

[35] T. L. Miller and M. J. Wolin, "Fermentations by saccharolytic intestinal bacteria," American Journal of Clinical Nutrition, vol. 32, no. 1, pp. 164-172, 1979.

[36] G. T. Macfarlane and G. R. Gibson, "Carbohydrate fermentation, energy transduction and gas metabolism in the human large intestine," in Gastrointestinal Microbiology, R. I. Mackie and B. A. White, Eds., vol. 1, pp. 269-318, Chapman \& Hall, New York, NY, USA, 1997.

[37] P. B. Mortensen, K. Holtug, and H. S. Rasmussen, "Shortchain fatty acid production from mono- and disaccharides in a fecal incubation system: Implications for colonic fermentation of dietary fiber in humans," Journal of Nutrition, vol. 118, no. 3, pp. 321-325, 1988.

[38] H. Hove, I. Nordgaard-Andersen, and P. B. Mortensen, "Effect of lactic acid bacteria on the intestinal production of lactate and short-chain fatty acids, and the absorption of lactose," American Journal of Clinical Nutrition, vol. 59, no. 1, pp. 7479, 1994.

[39] S. A. Brooks, M. V. Dwek, and U. Schumacher, Functional and Molecular Glycobiology, BIOS Scientific, Oxford, UK, 2002.

[40] F. Depeint, G. Tzortzis, J. Vulevic, K. I’Anson, and G. R. Gibson, "Prebiotic evaluation of a novel galactooligosaccharide mixture produced by the enzymatic activity of Bifidobacterium bifidum NCIMB 41171, in healthy humans: a randomized, double-blind, crossover, placebo-controlled intervention study," American Journal of Clinical Nutrition, vol. 87, no. 3, pp. 785-791, 2008.

[41] A. Bernalier, J. Dore, and M. Durand, "Biochemistry of fermentation," in Colonic Microbiota, Nutrition and Health, G. R. Gibson and M. B. Roberfroid, Eds., pp. 37-53, Kluwer Academic Publishers, Dordrecht, The Netherlands, 1999.

[42] V. Van Craeyveld, K. Swennen, E. Dornez et al., "Structurally different wheat-derived arabinoxylooligosaccharides have different prebiotic and fermentation properties in rats," Journal of Nutrition, vol. 138, no. 12, pp. 2348-2355, 2008.

[43] M. L. Sanz, G. R. Gibson, and R. A. Rastall, "Influence of disaccharide structure on prebiotic selectivity in vitro," Journal of Agricultural and Food Chemistry, vol. 53, no. 13, pp. 51925199, 2005.

[44] P. Brobech Mortensen and I. Nordgaard-Andersen, "The dependence of the in vitro fermentation of dietary fibre to short-chain fatty acids on the contents of soluble non-starch polysaccharides," Scandinavian Journal of Gastroenterology, vol. 28, no. 5, pp. 418-422, 1993.

[45] M. L. Sanz, G. L. Côté, G. R. Gibson, and R. A. Rastall, "Prebiotic properties of alternansucrase maltose-acceptor oligosaccharides," Journal of Agricultural and Food Chemistry, vol. 53, no. 15, pp. 5911-5916, 2005.

[46] M. L. Sanz, G. L. Côté, G. R. Gibson, and R. A. Rastall, "Selective fermentation of gentiobiose-derived oligosaccharides by human gut bacteria and influence of molecular weight," FEMS Microbiology Ecology, vol. 56, no. 3, pp. 383-388, 2006. 


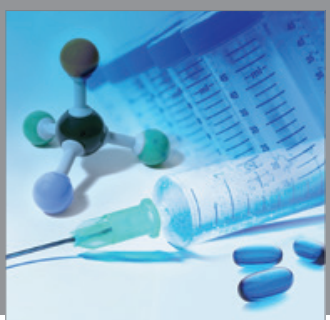

International Journal of

Medicinal Chemistry

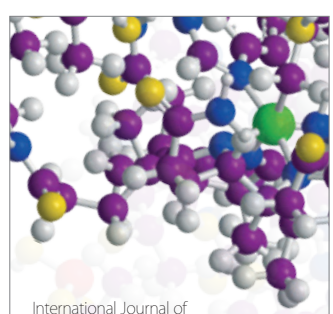

Carbohydrate Chemistry

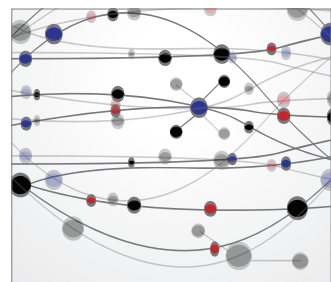

The Scientific World Journal
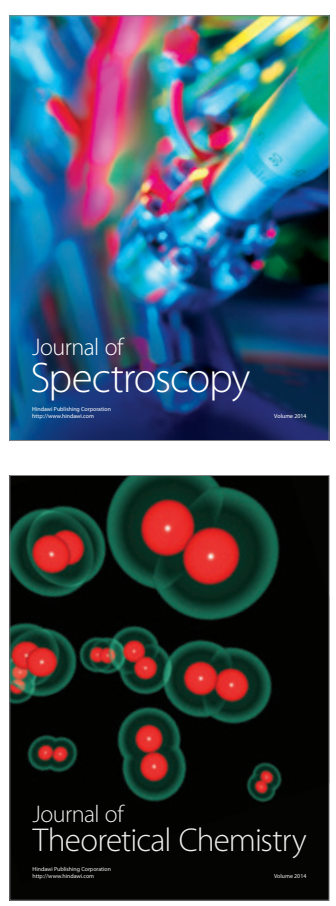
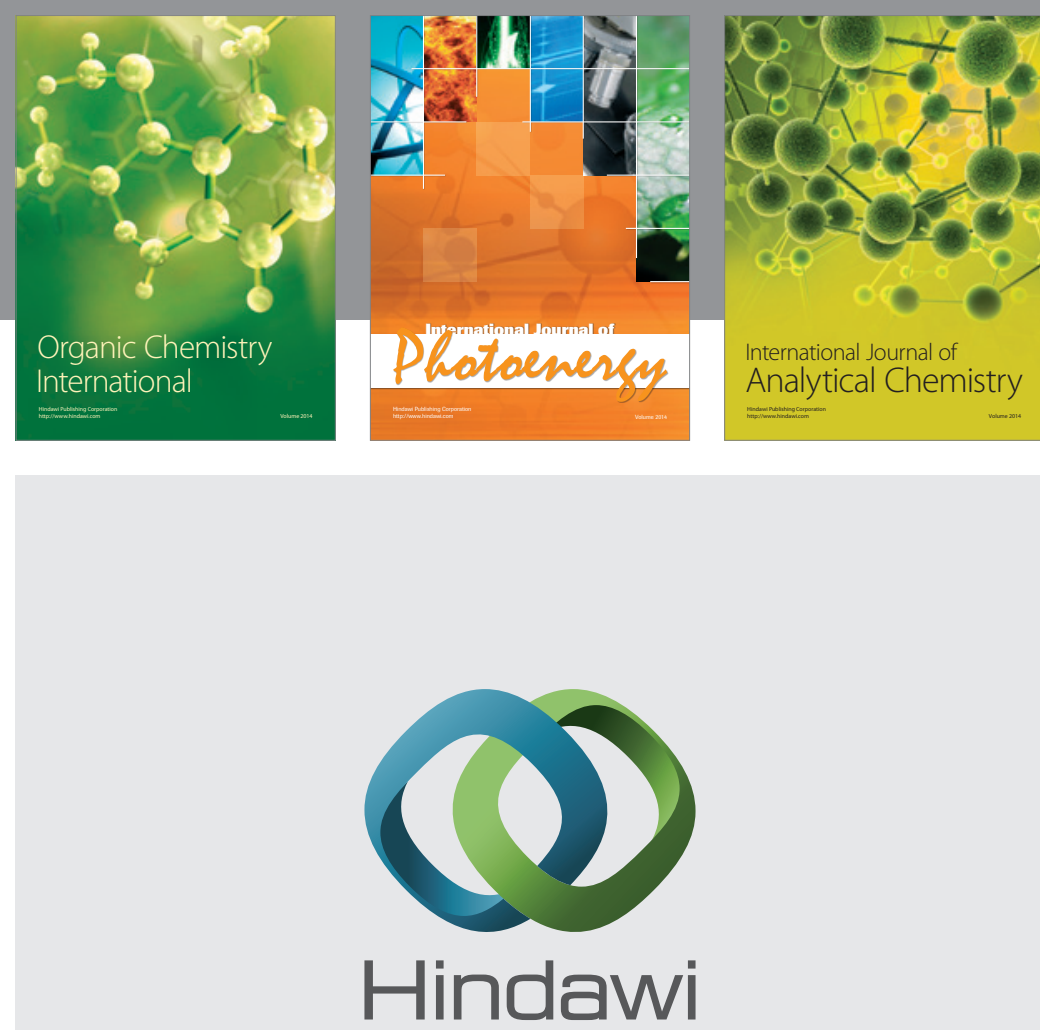

Submit your manuscripts at

http://www.hindawi.com
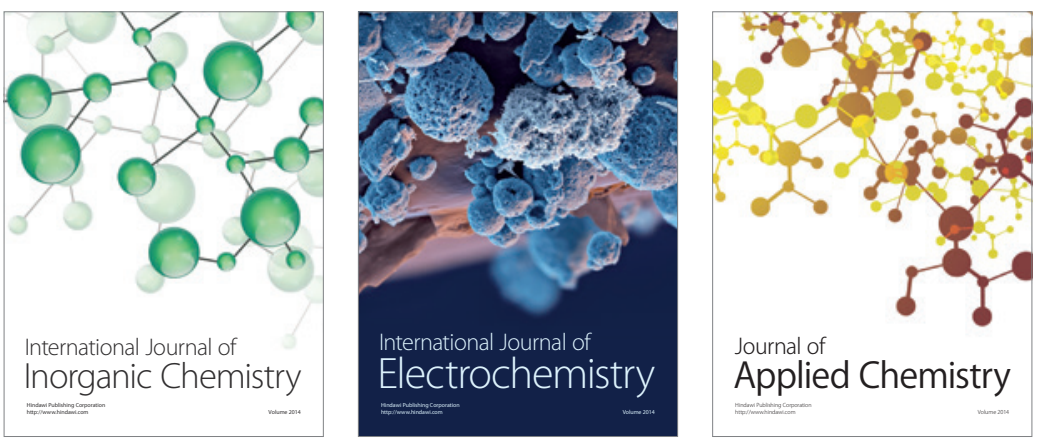

Journal of

Applied Chemistry
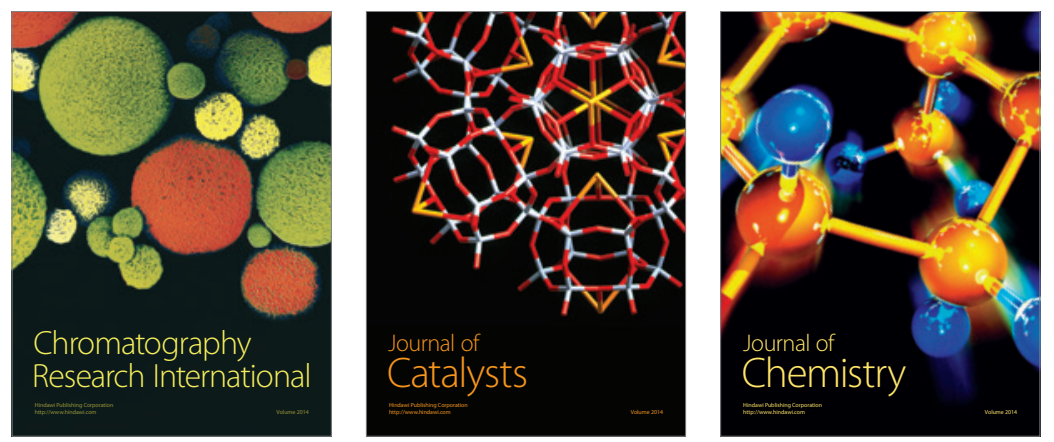
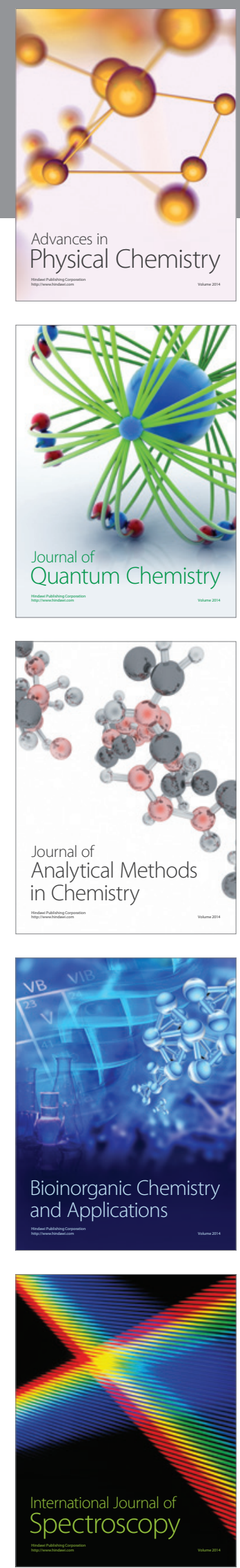